\title{
Meta-analysis on dose-response relationship of inhaled steroids must be done in homogenous asthma populations
}

\author{
To the Editor:
}

We would like to draw the readers' attention to the results of the meta-analysis of dose-response of inhaled budesonide in the recent article by MASOLI et al. [1], as we think these should be interpreted with great caution.

The dose-response relationship of inhaled steroids in asthma continues to be a topic of discussion, and even after 20 yrs there is no consensus on exactly which dose to use for an individual asthma patient. However, one of the experiences we, and certainly others, have gained is that the dose-response curves differ greatly in different asthma populations and are very much dependent on both the severity of the disease and also on asthma duration. In the latter case, the shorter the duration the lower the dose needed. Although MASOLI et al. [1] have excluded studies if they were not placebo-controlled or involved oral steroid-dependent patients, this does not mean that the rest of the asthma population in their metaanalysis is homogenous. Thus the overall approach for the dose-response exercise taken by MASOLI et al. [1] needs careful scrutiny, and the dose ranges found may indeed mislead the prescribing physician to use standardised, instead of individualised, doses.

In addition, there are concerns regarding the methodology used for the dose calculations in MAsoli et al. [1]. First, the

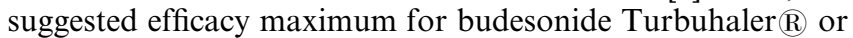
Nebuhaler $\mathbb{R}$ was arbitrarily chosen to be $1,600 \mu \mathrm{g} \cdot \mathrm{day}^{-1}$ without giving any reason. Secondly, the use of a metaregression approach to compare the effect of change in dose is less than ideal, as this model implies that a local maximal effect is achieved, which we know is not the case with inhaled steroids because they reach an efficacy plateau. Thirdly, a further weakness in the analysis is the approach of comparing the $400 \mu \mathrm{g} \cdot \mathrm{day}^{-1}$ dose with the nearest higher dose. Most of our experience tells us that no difference in clinical efficacy will be detected, for example, when doubling the dose of inhaled steroids.

Regarding the relationship between budesonide and other inhaled steroids, even more caution is required when evaluating clinical findings. It is not possible to compare the results of the meta-analysis performed on fluticasone [2] with the study by MASOLI et al. [1], again with the differences in patient populations in mind. In HoLT et al. [2] there is also an overall flaw seen by the consistent use of lower doses of fluticasone in the analysed studies. Ideally, the budesonide studies should have included more dose-steps in the range of $100-200 \mu \mathrm{g}$, but regrettably such data is not available. However, this reflects the changes in treatment strategies over time and not necessarily any potency differences.

In order to get valid data for the dose-response relationships of inhaled steroids, we believe in performing more studies in defined populations and ideally using several doses of each drug. Also, dose-reduction studies can be used, especially when comparing different steroids or steroid-device combinations. Hopefully most readers are aware that we have used such designs both for the relationship between budesonide Turbuhaler versus the pressurised metered dose inhaler [3], as well as for the relationship between budesonide Turbuhaler and fluticasone Diskhaler and Diskus [4, 5], an approach that was very much endorsed in an editorial in the European Respiratory Journal 3 yrs ago [6].

\author{
J. Ingelf, J. Ekelund, L-G. Carlsson \\ AstraZeneca PS\&L, Lund, Sweden.
}

\section{References}

1. Masoli M, Holt S, Weatherall M, Beasley R. Dose-response relationship of inhaled budesonide in adult asthma: a metaanalysis. Eur Respir J 2004; 23: 552-559.

2. Holt S, Suder A, Weatherall M, Cheng S, Shirtcliffe P, Beasley R. Dose-response relation of inhaled fluticasone propionate in adolescents and adults with asthma: metaanalysis. BMJ 2001; 323: 253-256.

3. Agertoft L, Pedersen S. Importance of the inhalation device on the effect of budesonide. Arch Dis Child 1993; 69: 130-133.

4. Agertoft L, Pedersen S. A randomized, double-blind dose reduction study to compare the minimal effective dose of budesonide Turbuhaler and fluticasone propionate Diskhaler. J Allergy Clin Immunol 1997; 99: 773-780.

5. Kuna P, Joubert J, Greefhorst APM, Magnussen H. A randomized, double-blind, double-dummy, parallel-group, multicenter, dose-reduction trial of the minimal effective doses of budesonide and fluticasone dry-powder inhalers in adults with mild to moderate asthma. Clin Ther 2003; 25: 2182-2197.

6. Beasley R, Sterk PJ, Kerstjens HAM, Decramer M. Comparative studies of inhaled corticosteroids in asthma. Eur Respir J 2001; 17: 579-580.

\section{From the authors:}

It is helpful to have the opportunity to respond to the letter of J. Ingelf and colleagues to clarify issues relating to the metaanalysis of the dose-response relationship of budesonide in the treatment of adult asthma [1].

The ideal way to explore the relationship between dose and response amongst individuals with different characteristics, such as severity or duration of disease, would be by metaanalysis of individual patient data. Unfortunately, only summary response data were available; a useful extension of our work would have been possible if our attempts to access individual patient data from AstraZeneca had been successful. This point regarding access to individual patient data held by pharmaceutical companies was made in an accompanying editorial with reference to our work on the dose-response relationship of fluticasone [2]. Pending the analysis and publication of these data, we recommend that physicians should prescribe in accordance with the therapeutic dose range, which has been defined in our meta-analysis based on available scientific data.

In response to the methodological issues, the effect obtained with $1,600 \mu \mathrm{g} \cdot \mathrm{day}^{-1}$ was considered to be the "maximum effect", as this was the highest dose used in the studies included in the meta-analysis. It will be possible to examine the effects with higher doses if dose-response studies including high doses are undertaken. No attempt was made to determine the dose-response relationship of local side-effects. Indeed, the systemic adverse effects are of considerably greater 
importance than local adverse effects and, in this respect, we refer back to the study by AARONSON et al. [3] discussed in the manuscript, in which 6 weeks of $3,200 \mu \mathrm{g} \cdot$ day $^{-1}$ budesonide treatment led to the suppression of adrenal cortisol production of a magnitude similar to that observed with $10 \mathrm{mg}$ of oral prednisone. With regard to the regression using a quadratic term, this is a standard approach to the modelling of curvature, and was consistent with both the exponential model, fitted numerically, and with the analysis comparing $400 \mu \mathrm{g} \cdot \mathrm{day}^{-1}$ of budesonide versus higher doses.

The comparison in efficacy of $400 \mu \mathrm{g} \cdot \mathrm{day}^{-1}$ budesonide versus higher doses addresses an important clinical question: what is the probable magnitude of benefit of increasing the dose of budesonide if the asthmatic patient is not well controlled with budesonide at a dose of $400 \mu \mathrm{g} \cdot \mathrm{day}^{-1}$ ? This analysis showed small nonsignificant differences, findings consistent with the other analyses undertaken, indicating that most of the therapeutic benefit is obtained with a $400 \mu \mathrm{g} \cdot \mathrm{day}^{-1}$ budesonide dose. In terms of the efficacy of doses higher than those included in the meta-analysis, there has been only one randomised double-blind study that compared doses of budesonide $>1,600 \mu \mathrm{g} \cdot \mathrm{day}^{-1}$ [4]. In this study, there was no therapeutic difference between 8 weeks of treatment with 3,200 and $1,600 \mu \mathrm{g} \cdot \mathrm{day}^{-1}$, confirming the lack of further benefit at very high doses.

In terms of dose-response studies that have examined either very low $\left(<200 \mu \mathrm{g} \cdot \mathrm{day}^{-1}\right)$ or very high $\left(>1,600 \mu \mathrm{g} \cdot \mathrm{day}^{-1}\right)$ doses, we agree that there is little current available literaturebased evidence to guide clinicians. This represents a gap in current knowledge and should be a stimulus for further research; however, it does not affect the interpretation of the available literature. Our understanding of the optimal use of inhaled budesonide in asthma will improve with the publication of additional controlled trials and analyses based on individual patient data from existing research, both published and unpublished. AstraZeneca is in an ideal position to contribute to this advancement in knowledge.
Whilst recognising that the relative potency between budesonide and fluticasone is a controversial issue, the budesonide [1] and fluticasone analyses [5] would suggest a $1: 2$ ratio for their clinical effects.

In summary, our meta-analysis presents the data that are available from scientific studies and have examined the doseresponse relationship of inhaled budesonide in adults. Whilst recognising that there is marked individual variability in response to inhaled corticosteroids, which would suggest that some patients may obtain a greater clinical benefit at higher doses, just as some patients may obtain the maximum effect at lower doses, we recommend that physicians should prescribe in accordance with the therapeutic dose range defined in the meta-analysis

M. Masoli, M. Weatherall, S. Holt, R. Beasley

Medical Research Institute of New Zealand, Wellington, New Zealand.

\section{References}

1. Masoli M, Holt S, Weatherall M, Beasley R. Dose-response relationship of inhaled budesonide in adult asthma: a metaanalysis. Eur Respir J 2004; 23: 552-558.

2. Herxheimer A. Commentary: dosage needs systematic and critical review. BMJ 2001; 323: 257.

3. Aaronson D, Kaiser H, Dockhorn R, et al. Effects of budesonide by means of the Turbuhaler on the hypothalamic-pituitary-adrenal axis in asthmatic subjects: a doseresponse study. J Allergy Clin Immunol 1998; 101: 312-319.

4. Reddel H, Jenkins C, Marks G, et al. Optimal asthma control starting with high doses of inhaled budesonide. Eur Respir J 2000; 16: 226-235.

5. Holt S, Suder A, Weatherall M, Cheng S, Shirtcliffe P, Beasley R. Dose-response relation of inhaled fluticasone propionate in adolescents and adults with asthma: metaanalysis. BMJ 2001; 323: 253-256. 